\title{
Decision making, cognitive distortions and emotional distress: A comparison between pathological gamblers and healthy controls
}

Article in Journal of Behavior Therapy and Experimental Psychiatry · August 2016

DOI: 10.1016/j.jbtep.2016.08.012

CITATIONS

0

4 authors:

Maria Ciccarelli

Second University of Naples

7 PUBLICATIONS 5 CITATIONS

SEE PROFILE

Giovanna Nigro

Second University of Naples

44 PUBLICATIONS 198 CITATIONS

SEE PROFILE
READS

74
Mark D Griffiths

Nottingham Trent University

805 PUBLICATIONS $\quad \mathbf{1 8 , 4 2 6}$ CITATIONS

SEE PROFILE

Marina Cosenza

4. Second University of Naples

21 PUBLICATIONS 52 CITATIONS

SEE PROFILE 
Decision making, cognitive distortions and emotional distress: a comparison between pathological gamblers and healthy controls

Maria Ciccarelli ${ }^{\mathrm{a}}$, Mark D. Griffiths ${ }^{\mathrm{b}}$, Giovanna Nigro ${ }^{\mathrm{a}}$, Marina Cosenza ${ }^{\mathrm{a}}$

a Department of Psychology, Second University of Naples, Viale Ellittico, 31, 81100 Caserta, Italy

b Psychology Division, Department of Social Sciences, Nottingham Trent University, Nottingham NG1 4BU, United Kingdom

Corresponding author: Maria Ciccarelli, viale Ellittico, 31, 81100 Caserta, Italy;

e-mail: maria.ciccarelli@unina2.it 


\section{Abstract}

Background and objectives: The etiology of problem gambling is multifaceted and complex. Among others factors, poor decision making, cognitive distortions (i.e., irrational beliefs about gambling), and emotional factors (e.g., negative mood states) appear to be among the most important factors in the development and maintenance of problem gambling. Although empirical evidence has suggested that cognitive distortions facilitate gambling and negative emotions are associated with gambling, the interplay between cognitive distortions, emotional states, and decision making in gambling remains unexplored.

Methods: Pathological gamblers $(N=54)$ and healthy controls $(N=54)$ completed the South Oaks Gambling Screen (SOGS), the Iowa Gambling Task (IGT), the Gambling Related Cognitions Scale (GRCS), and the Depression Anxiety Stress Scale (DASS-21).

Results: Compared to healthy controls, pathological gamblers showed poorer decision making and reported higher scores on measures assessing cognitive distortions and emotional distress. All measures were positively associated with gambling severity. A significant negative correlation between decision making and cognitive distortions was also observed. No associations were found between poor decision making and emotional distress. Logistic regression analysis indicated that cognitive distortions, emotional distress, and poor decision making were significant predictors of problem gambling.

Limitations: The use of self-report measures and the absence of female participants limit the generalizability of the reported findings.

Conclusions: The present study is the first to demonstrate the mutual influence between irrational beliefs and poor decision making, as well as the role of cognitive bias, emotional distress, and poor decision making in gambling disorder.

Keywords: Pathological gambling; Gambling disorder; Decision making; Cognitive distortions; Emotional distress. 


\section{Introduction}

Gambling disorder has been defined as a "persistent and recurrent problematic gambling behavior leading to clinically significant impairment or distress" (American Psychiatric Association, 2013; p.585). The negative consequences arising from gambling (e.g., occupational, relationship, and/or financial problems) do not necessarily deter problem gambling. In fact, counter intuitively, many individuals with a gambling disorder are typically unable to cease the problematic behavior and are prone to chasing losses in an attempt to recover the money lost (Lesieur, 1979; Linnet, Røjskjær, Nygaard, \& Maher, 2006). Furthermore, it has been empirically demonstrated that problem gamblers show a foreshortened time horizon, since they are likely to consider the immediate consequences rather than the long-term outcomes (Ciccarelli, Malinconico, Griffiths, Nigro, \& Cosenza, 2016; Nigro, Cosenza, Ciccarelli, \& Joireman, 2016; Cosenza, Griffiths, Nigro, \& Ciccarelli, 2016).

Although the etiology of gambling disorder is complex and multifaceted, several studies have identified poor decision making (Wiehler \& Peters, 2015), cognitive distortions (Goodie \& Fortune, 2013), and emotional distress (Lorains, Cowlishaw, \& Thomas, 2011) as among the most critical factors associated with problem gambling. However, no study to date has taken into account the interplay of these factors when examining gambling disorder. A large body of research has indicated that problem gamblers perform more poorly than healthy controls in behavioral decision making tasks (see Wiehler \& Peters, 2015 for a review), such as the Iowa Gambling Task (IGT; Bechara, Damasio, Damasio, \& Anderson, 1994). The IGT is a laboratory task that mimics real-life decisions in conditions of reward and punishment, as well as decision making under uncertainty.

Originally, the IGT was developed to capture decision making fallacies in patients with ventromedial cortex damage (Bechara et al., 1994; Bechara, Damasio, Tranel, \& Damasio, 2005). These patients showed a compromised ability to experience and/or to express appropriate emotions, as well as impaired decision making ability, while preserving a normal intellect. Starting from these observations, Damasio, Tranel, and Damasio (1991) formulated the somatic marker hypothesis (SMH; Damasio, 1994). The SMH states that emotions are important features in choice processing as they can guide or bias (consciously or unconsciously) decision making behavior. The SMH postulates that decision making process can be assisted by somatic markers (i.e., specific types of feelings expressed through somatic states). The somatic markers are represented and regulated in the ventromedial prefrontal cortex, which associates the implicit representations of affects with the explicit representations of potential actions and outcomes. In this way, the somatic markers influence decisions, acting as alarms for bad choices or incentives for good choices (Damasio, 1994).

Similarly to ventromedial prefrontal patients, gamblers appear unable to consider long-term benefits, probably due to a lack of response flexibility or chasing losses (see Goudriaan, Oosterlaan, de Beurs, \& van den Brink, 2005; Kertzman, Lidogoster, Aizer, Kotler, \& Dannon, 2011; Linnet et al., 2006). According to other authors, poor decision 
making stems from a decreased reward sensitivity (Goudriaan, Oosterlaan, de Beurs, \& van den Brink, 2006), an excessive response to cues predicting immediate and large monetary rewards (Brevers, Bechara, Cleeremans, \& Noël, 2013, p. 9; see also Lakey, Goodie, \& Campbell, 2007), an anomalous reward processing (Lorains et al., 2014), or disrupted basic emotional processing (Brevers et al., 2012).

Cognitive distortions concern misbeliefs about gambling outcomes and the likelihood of influencing them (Clark et al., 2013; Griffiths, 1994; Goodie \& Fortune, 2013; Jacobsen, Knudsen, Krogh, Pallesen, \& Molde, 2007), such as skill misperceptions, illusion of control, superstitious beliefs, selective memory for wins, and interpretative biases (Toneatto, 1999).

Converging evidence from studies examining the association between cognitive distortions and problematic gambling have demonstrated that gamblers tend to misattribute cause-and-effect relationships to unlinked events, and believe they can influence gambling outcomes (e.g., Cosenza \& Nigro, 2015; Joukhador, Blaszczynski, \& Maccallum, 2004; Myrseth, Brunborg, \& Eidem, 2010). Interestingly, several studies suggest that the appropriate use of mathematical and probabilistic rules in daily life do not appear to be a protective factor from gambling (Benhsain \& Ladouceur, 2004; Delfabbro, Lahn, \& Grabosky, 2006; Sévigny \& Ladouceur, 2003). However, even though nonproblem gamblers are unable to profit from the knowledge of probabilistic rules (e.g., Joukhador, Maccallum, \& Blaszczynski, 2003), many aspects differentiate them from problematic gamblers in terms of quantity (e.g., Ciccarelli, Griffiths, Nigro, \& Cosenza, 2016; Miller \& Currie, 2008) and quality of distorted beliefs (e.g., Källmen, Andersson, \& Andren, 2008). However, arguably the most relevant aspect regards the insensitivity to disconfirming evidence (Ladouceur, 2004).

Finally, research has indicated that problem gambling is frequently associated with negative affective states, such as negative mood (Griffiths, 1995; Matthews, Farnsworth, \& Griffiths, 2009) and/or anxiety disorders (e. g., Kessler et al., 2008; Petry, Stinson, \& Grant, 2005). More specifically, some epidemiological surveys suggest that nearly half of all problem gamblers suffer from mood disorders (e.g., Kim, Grant, Eckert, Faris, \& Hartman, 2006; Lorains et al., 2011), and that pathological gamblers undergoing treatment report severe depression (Ladouceur et al., 2006). Other studies have provided evidence that individuals may use gambling for mood modification, that is to find relief from negative states and to increase arousal when bored (e.g., Nower \& Blaszczynski, 2010; Stewart, Zack, Collins, Klein, \& Fragopoulos, 2008; Wood \& Griffiths, 2007; Wulfert, Roland, Hartley, Wang, \& Franco, 2005). Gee, Coventry and Birkenhead (2005) found higher levels of anxiety during and after gambling and concluded that gambling could result in mood modification. Finally, experimental studies attempting to clarify the causal relationship between mood and gambling severity have highlighted differences in mood before and after gambling, but have failed to find 
effects of induced mood on gambling (e.g., Hills, Hill, Mamone, \& Dickerson, 2001; Mishra, Morgan, Lalumière, \& Williams, 2010).

Given that no study to date has ever examined the relationship among decision making, cognitive distortions, and negative affective states in pathological gambling, the aim of the present study was to investigate the interplay among these variables by comparing pathological gamblers and healthy controls. It was hypothesized that compared to healthy controls, pathological gamblers would show (a) poorer decision making ability, (b) higher levels of cognitive distortions, and (c) higher levels of emotional distress. It was also hypothesized that there would be strong correlations between these variables and gambling severity.

\section{Material and methods}

\subsection{Participants}

The sample comprised 108 males aged 24 to 65 years (mean age $=41.56$ years; $S D=10.94$ ). Of these, 54 were pathological gamblers (PGs) with a DSM-5 (APA, 2013) diagnosis of gambling disorder, and recruited from Local Health Trusts. The pathological gamblers were matched with 54 healthy controls (HCs) recruited from the community. No pathological gamblers had comorbid mental disorders, neurological and/or medical illnesses, or were undergoing any pharmacological treatment. Healthy controls had no psychiatric and/or neurological disorders. Pathological gamblers reported scores on the South Oaks Gambling Screen (SOGS; Lesieur \& Blume, 1987) equal or higher than 5 (out of 20), whereas healthy controls reported SOGS scores lower than or equal to 2. There was no difference in the two samples in term of age $\left(\mathrm{HCs}=41.02\right.$ years, $\mathrm{PGs}=42.09$ years; $\left.\mathrm{t}_{106}=-.48, p=0.63\right)$, or years of education $(\mathrm{HCs}=11.39$ years, PGs $=10.50$ years; $\mathrm{t}_{106}=1.59, p=0.12$ ).

\subsection{Measures}

\section{Problem gambling}

The South Oaks Gambling Screen (SOGS; Lesieur \& Blume, 1987; Italian translation: Cosenza, Matarazzo, Baldassarre, \& Nigro, 2014) assesses the severity of gambling involvement. The SOGS is a screening instrument based on DSM-III criteria for pathological gambling (APA, 1980) that comprises 20 scored items, assessing gambling behavior and gambling-related problems during the person's lifetime. The total score ranges from 0 to 20 . In addition to the scored items, the SOGS requests participants to indicate, among others, the frequency of participation in different gambling activities, the largest amount of money gambled in one day, and parental involvement in gambling. Based on SOGS scores, individuals are classified as non-problem gamblers (score 0-2), problem gamblers (score 3-4), or 
probable pathological gamblers (score > 5). SOGS in the present study had a high internal consistency reliability coefficient (Cronbach's alpha $=.93,95 \%$ CI $[.92, .94])$.

\section{Decision making}

The Iowa Gambling Task (IGT; Bechara et al., 1994) is a computerized assessment of decision making processes using four card decks, varying in amount of monetary reward and punishment and in the frequency of losses over a total of 100 trials. In the IGT, participants make a series of choices from a set of four computerized 'decks of cards' labeled A, $\mathrm{B}, \mathrm{C}$, and D, respectively. At the beginning of the task, participants are given a loan of $\$ 2000$ and asked to play with the aim of earning as much money as possible. Deck A and deck B (disadvantageous decks) yield large immediate monetary gains but larger monetary losses in the long-term, whereas deck C and deck D (advantageous decks) result in small immediate monetary gains but smaller long-term losses. Playing mostly from disadvantageous decks leads to an overall loss, while playing from advantageous decks leads to an overall gain. The players cannot predict when a penalty will occur, nor calculate with precision the net gain or loss from each deck. Because it is impossible to calculate the best option from the beginning of the task, players have to learn to avoid bad decks by following their feeling and hunches, and by using the feedback they get after each choice. Performance on the IGT is computed by subtracting the number of disadvantageous choices (A, B) from the number of advantageous choices (C, D) on the complete task, and for each block of 20 cards to evaluate changes in decision making strategies. A global score below 10 (out of 100) is indicative of a decision making deficit (Bechara \& Damasio, 2002).

\section{Cognitive distortions}

The Gambling Related Cognitions Scale (GRCS; Raylu \& Oei, 2004; Italian validation: Iliceto et al., 2015) is a 23-item instrument that was developed to identify common gambling distortions on five subscales. The Gambling-related Expectancies (GE) subscale focuses on expected benefits from gambling; Illusion of Control (IC) reflects cognitions relating to ability to control gambling outcomes; Predictive Control (PC) focuses on probability errors (such as gambler's fallacy); and Inability to Stop gambling (IS) examines respondents' perceived inability to control their gambling behavior. Lastly, Interpretative Bias (IB) reflects cognitions relating to reframing gambling outcomes to encourage further play. Participants are requested to indicate the extent to which they agree with each statement on a 7point scale, ranging from 1 (strongly disagree) to 7 (strongly agree), with higher scores reflecting an elevated number of cognitive errors. In the present study, the internal consistency for the total scale $(\alpha=.91,95 \% \mathrm{CI}[.89, .93])$ and for each scale was adequate: $\mathrm{GE}(\alpha=.71,95 \% \mathrm{CI}[.61, .79]), \mathrm{IC}(\alpha=.68,95 \% \mathrm{CI}[.57, .77]), \mathrm{PC}(\alpha=.73,95 \% \mathrm{CI}[.65, .81])$, IS $(\alpha=.81,95 \%$ CI $[.75, .86])$, and IB $(\alpha=.80,95 \%$ CI $[.73, .85])$. 


\section{Emotional distress}

The Depression Anxiety Stress Scales 21 (DASS-21; Lovibond \& Lovibond, 1995; Italian validation: Bottesi et al., 2015) is a self-report measure assessing the three related negative affective states of depression, anxiety, and stress. The Depression scale includes items that assess symptoms typically associated with dysphoric mood, such as sadness, worthlessness, lack of interest or involvement, and low self-esteem (example item: "I felt that I had nothing to look forward to"). The Anxiety scale assesses symptoms of physical arousal, panic attacks, and subjective experience of fear (e.g., "I felt scared without any good reason"). The Stress scale assesses symptoms such as difficulty relaxing, impatience, and being easily upset, irritable or overreactive (e.g., "I felt that I was rather touchy"). Respondents are asked to indicate how much each statement applied to them during the previous week on a 4-point scale ranging from 0 (did not apply to me at all) to 3 (applied to me very much, or most of the time). Higher scores indicate severe emotional distress. In the present study, Cronbach's alpha for the full scale was .95 (95\% CI [.93-.96]), .92 (95\% CI [.89-.94]) for the depression dimension, .87 (95\% CI [.83-.90]) for the anxiety subscale, and .88 (95\% CI [.85-.91]) for the stress subscale.

\subsection{Procedure}

The study was approved by the Ethics Committee of the Department of Psychology of the first author's university. Prior to participation, all participants provided informed consent. Participants were tested individually. For all participants, the IGT task was administered first, followed by the self-report measures. At the end of the session, participants were debriefed and thanked for their participation.

\subsection{Statistical analyses}

Data were analyzed with the IBM Statistical Package for the Social Sciences, version 20.0. The alpha significance level was set at $p=.05$. Preliminarily, Pearson's correlations among all variables were computed. To ascertain whether the two groups differed on the total scores of the IGT, GRCS, and DASS-21, three separate univariate ANOVAs were performed. Furthermore, a mixed-model ANOVA was run to compare the IGT profile of the two groups. Two multivariate analyses of variance (MANOVA) with the group as independent variable and the subscales of GRCS and DASS-21 as dependent factors were performed to verify whether these variables differed significantly between groups. Finally, to assess the relative contribution of decision making, cognitive distortions, and negative affective states for gambling involvement, a hierarchical logistic analysis was run using the two groups as the criterion variable with the total scores of behavioral and self-report measures used as predictors. 


\section{Results}

Zero-order correlations revealed significant positive associations between all measures and problem gambling severity, as well as between IGT and GRCS scores (Table 1).

\section{INSERT TABLE 1 ABOUT HERE}

For analyzing the profile of the IGT performances of the two groups per block, a 2X5 repeated measures ANOVA was run, with group (HCs versus PGs) as a between-subjects factor and scores on the five subsequent IGT blocks as dependent variables. The analysis revealed a significant within-subjects effect of block $\left(F_{4,103}=8.27 ; p<.001\right.$, $\eta_{p}^{2}=.24$ ), indicating an improvement of all participants' performance across the IGT blocks, and a main effect of group $\left(F_{1,106}=12.69 ; p<.001, \eta_{p}^{2}=.11\right)$, with pathological gamblers performing worse than healthy controls (see Figure 1). No significant block X group interaction was observed $\left(F_{4,103}=0.97 ; p=.43\right)$.

\section{INSERT FIGURE 1 ABOUT HERE}

Results of ANOVAs indicated that, relative to controls, pathological gamblers performed poorer on the IGT $\left(F_{1,106}=12.69 ; p<.001, \eta^{2}=.11\right)$ and reported higher scores on the GRCS total score and on all its subscales.

Furthermore, pathological gamblers scored significantly higher than healthy controls on the DASS-21 total score, as well as on both the Depression and the Anxiety subscales, whereas the difference on the Stress dimension fell short of significance. Means and standard deviations for all measures are reported in Table 2.

\section{INSERT TABLE 2 ABOUT HERE}

A logistic regression identified the predictors of problem gambling severity. Total GRCS and DASS-21 scores were used along with performance on the IGT as predictors. Cognitive distortions (GRCS scores) significantly predicted problem gambling severity, $\chi^{2}(1, N=108)=39.20, p<.001$, with $41 \%$ of the explained variance (Nagelkerke $\left.\mathrm{R}^{2}\right)$. The addition of emotional distress (DASS-21 scores) to the model was significant, $\chi^{2}(2, N=108)=46.87, p<.001$, adding $6 \%$ of the explained variance to the model. In the final step, the addition of decision making performance (IGT scores) was significant, $\chi^{2}(3, N=108)=52.83, p<.001$, and added a further $5 \%$ of the explained variance to the model. The betas indicated that cognitive distortions, high level of depression, anxiety, stress, and poor decision making resulted in a higher likelihood of problem gambling severity. The percentage of explained variance of the full model was $52 \%$, with an overall classification accuracy of $77 \%$ (see Table 3 ).

\section{TABLE 3 ABOUT HERE}

\section{Discussion}

The present study addressed an identified gap in literature regarding the relationship between pathological gambling, decision making, cognitive distortions, and emotional factors (i.e., depression, anxiety and stress). This was achieved in an experimental task comparing a group of confirmed pathological gamblers with a group of healthy controls, and 
determining which of these factors most accounted for gambling disorder. As expected, a negative correlation between IGT scores and problem gambling severity was observed, indicating that the more severe the gambling involvement is, the more impaired decision making is, confirming previous studies (e.g., Brevers et al., 2012; Lakey et al., 2007). The decision making deficit found among pathological gamblers compared to healthy controls supports a large body of literature showing that problem gamblers have an insensitivity to future consequences and an inability to project themselves in the future (e.g., Ciccarelli, Griffiths, et al., 2016; Linnet et al., 2006). They appear unable to forego immediate and conspicuous rewards in order to obtain rewards that would be profitable in long-term, and making shortterm choices of questionable utility (e.g., Lorains et al., 2014; Petry, 2001; Wiehler \& Peters, 2015). Indeed, according with Kertzmann et al.'s study (2011), in the present study pathological gamblers differed from healthy controls in both the overall IGT performance and in the sequence of choices. While healthy controls shifted their picks from disadvantageous toward advantageous decks over the course of the time (trials), pathological gamblers stayed with the disadvantageous decks, probably attracted by the high and immediate rewards. Assessing the physiological activation of gamblers during the IGT, Goudriaan et al. (2006) found reduced skin conductance responses when making poor decisions. The diminished psychophysiological activation in response to risky options indicated a difficulty in assessing risk, consequently promoting risky behavior.

The higher level of cognitive distortions among pathological gamblers (vs. healthy controls) confirmed previous studies (e.g., Cosenza, Baldassarre, Matarazzo, \& Nigro, 2014; Goodie \& Fortune, 2013; Taylor, Parker, Keefer, Kloosterman, \& Summerfeldt, 2015) in which problem gamblers have been found to report more and different gambling-related cognitive distortions compared to healthy controls. Specifically, in the present study, pathological gamblers were found to expect gambling to relieve negative states (such as boredom, stress, tension, or sadness), and believe that they can influence gambling outcomes via specific rituals, objects, and/or behaviors, in line with studies that have looked at the role of rituals and/or superstition in gambling (e.g., Griffiths \& Bingham, 2005; Reith, 2002). Furthermore, gamblers distort the meaning of losses, often conceive losses as near wins (Griffiths, 1999), and trust in their ability to predict future gambling outcomes (e.g., Griffiths, 1994). They are committed to continued gambling and make misjudgments when they attribute their wins to personal factors and their losses to external and environmental factors as bad luck. Irrational beliefs have been reported in the psychological literature as responsible for the continuation of gambling despite continued losses and the negative consequences (e.g., Fortune \& Goodie, 2012). In line with recent research on adolescent samples, the results of the present study indicated that the GRCS scores account for a substantial amount of the variance in pathological gambling (Ciccarelli, Griffiths, et al., 2016; Cosenza \& Nigro, 2015; Taylor, Parker, Keefer, Kloosterman, \& Summerfeldt, 2014). 
Correcting and restructuring these distortions can be used psychotherapeutically. Concerning treatment, Fortune and Goodie (2012) reviewed and compared the effectiveness of different types of psychotherapy approaches. They concluded that although the literature on the benefits arising from therapy is too small and heterogeneous, there is evidence supporting the effectiveness of individual cognitive-behavioral therapy (Dowling, Smith, \& Thomas, 2007) with a specific focus on the cognitive distortions restructuring (CR). Following treatment, gamblers showed a decreased gambling severity and an increased perception of control on their gambling behavior (Ladouceur et al., 2001, 2003).

As with previous literature, the present study found high correlation between gambling disorder and gamblingrelated irrational beliefs, confirming that severe problem gambling is associated with high level of cognitive distortions (Gaboury \& Ladouceur, 1989). For the first time, the present study found that poorer decision making was associated with higher cognitive distortion scores. Although the directionality of this relationship has not been established (and is beyond the present study's scope), this correlation is interesting because it suggests that the confidence in the ability to control or to predict gambling outcomes, along with other irrational beliefs, might heighten the decision making ability of pathological gamblers. This association leaves room for the possibility that a psychotherapeutic intervention on irrational beliefs may reduce the decision making deficit observed in gamblers population.

In contrast with Oei, Lin and Raylu (2008), who demonstrated a relationship between cognitive distortions and negative emotions, the present study did not confirm this association. However, it should be noted that Oei et al.'s (2008) sample comprised mostly of students that did not suffer from pathological gambling, whereas the present sample consisted of older participants, half of which met the DSM-5 criteria for gambling disorder. Differences in participant characteristics in the two studies may perhaps explain these contrasting results.

The present study demonstrates that pathological gambling correlated with negative emotional states. Specifically, the more individuals have a problematic gambling involvement, the more they experience anxiety and depression, confirming the findings of other studies (e.g., Barrault \& Varescon, 2013; Blaszczynski \& McConaghy, 1989; Coman, Burrows, \& Evans, 1997; Kim et al., 2006; Raylu \& Oei, 2002; Toneatto \& Pillai, 2016). For example, corroborating previous studies (e.g., Lorains et al., 2011), a recent systematic review and meta-analysis of the prevalence of co-morbid psychiatric Axis I disorders (DSM-IV; APA, 2000) among treatment-seeking problem gamblers demonstrated that mood and anxiety disorders are among the most common disorders that co-occur with problem gambling (23.1\% and 17.6\%, respectively) (Dowling et al., 2015).

At present, the directionality of the relationship between problem gambling and depression remains unknown. Indeed, it could be argued that depression foregoes problem gambling, which serves to relieve negative emotions and to avoid problems (Blaszczynski \& Nower, 2002). Nevertheless, it is equally conceivable that problematic gambling 
involvement progressively leads to depressive symptoms due to the resulting social isolation, and financial/legal problems (Dussault, Brendgen, Vitaro, Wanner, \& Tremblay, 2011).

The same holds true for anxiety. In line with the findings of the present study, Barrault and Varescon (2013), assessing psychological distress among different levels of gambling severity, found anxiety to be a good predictor of gambling problems. Similarly, it has been found that adult and adolescent gamblers with high levels of anxiety are more likely to meet the criteria for probable pathological gambling (El-Guebaly et al., 2006; Ste-Marie, Gupta, \& Derevensky, 2006). Even if it is difficult to determine whether anxiety is primary, secondary, or concurrent with gambling, one of the most consolidated theories concerning the relationship between anxiety and gambling - the “tension-reduction" hypothesis (Brady \& Lydiard, 1993) - posits that negative feelings, such as anxiety, can predispose individuals to engage in addictive behaviors to cope with bad feelings and that, in turn, the reduction of anxiety resulting from gambling reinforces and maintains the behavior.

In contrast with previous studies demonstrating the role of stress in the onset, maintenance (Coman et al., 1997; Elman, Tschibelu, \& Borsook, 2010; Friedland, Keinan, \& Regev, 1992), and relapse of gambling disorder (McCartney, 1995), no significant differences were found in the present study between pathological gamblers and healthy controls in relation to stress. This was most likely due to very little variability in the stress scores across the two groups.

Estimating the psychiatric co-morbidity in gambling is important for the clinical implications that it may have. For example, it has been recently demonstrated that comorbid mood disorder in gambling is associated with more severe gambling problems (Thomsen, Callesen, Linnet, Kringelbach, \& Møller, 2009; Quigley et al., 2015), that depression predicts a longer time to achieve abstinence from gambling (Hodgins, Peden, \& Cassidy, 2005), and that negative affects are a potential precipitant to relapse (Hodgins \& El-Guebaly, 2004). Thus, the evaluation of the comorbidity of gambling disorder may provide important information concerning treatment in order to identify the most suitable psychotherapeutic treatment to each individual case and for the prognosis/length of the treatment (Lorains et al., 2011).

The present study is not without limitations. The use of self-report measures limits the generalizability of the present study's results due to biases such as recall bias and social desirability. Furthermore, the findings in the present study cannot be generalized to female pathological gamblers since it only included males. Although sample size is another factor that could limit generalizability of results, it should be noted that the sample comprised gamblers with a confirmed DSM-5 clinical diagnosis and that, compared to other research in the literature, the number of pathological gamblers tested experimentally was arguably relatively large. 


\section{Conclusions}

The present study is the first ever to simultaneously examine the relationship between decision making, cognitive distortions, and emotional distress in a confirmed sample of pathological gamblers (compared to healthy controls).

In line with previous literature, the present study demonstrated that pathological gamblers showed deficits in decision making processes, and reported more irrational beliefs and higher levels of anxiety and depression compared to healthy controls. Additionally, the regression analyses demonstrated that cognitive distortions, emotional distress, and poor decision making are strong predictors of gambling disorder, accounting for $50 \%$ of the explained variance.

The novel finding of the association of poor decision making with higher levels of cognitive distortion suggests the possibility that cognitive bias might heighten the already poor decision making of pathological gamblers. The results also confirm the complexity of gambling disorder and the impact that different cognitive and emotional factors have upon it. Future studies should examine whether negative emotions are configured as a consequence of the repeated gambling or whether they act as a trigger of pathological-related behavior. Further studies should also investigate the relationship between decision making and cognitions more accurately, in order to determine its directionality. 


\section{Declaration of Interest}

All other authors declare that they have no conflicts of interest.

\section{Role of Funding Organizations}

No funding was provided for this study. 


\section{References}

American Psychiatric Association (1980). Diagnostic and Statistical Manual of Mental Disorders (3rd ed.). Washington DC: American Psychiatric Association.

American Psychiatric Association. (2000). Diagnostic and statistical manual of mental disorders (4th ed. Rev). Washington, DC: American Psychiatric Association.

American Psychiatric Association (2013). Diagnostic and Statistical Manual of Mental Disorders (5th ed.). Arlington, VA: American Psychiatric Publishing.

Barrault, S., \& Varescon, I. (2013). Cognitive distortions, anxiety, and depression among regular and pathological gambling online poker players. Cyberpsychology, Behavior, and Social Networking, 16(3), 183-188.

Bechara, A., \& Damasio, H. (2002). Decision-making and addiction (part I): Impaired activation of somatic states in substance dependent individuals when pondering decisions with negative future consequences. Neuropsychologia, 40(10), 1675-1689.

Bechara, A., Damasio, A. R., Damasio, H., \& Anderson, S. W. (1994). Insensitivity to future consequences following damage to human prefrontal cortex. Cognition, 50(1), 7-15.

Bechara, A., Damasio, H., Tranel, D., \& Damasio, A. R. (2005). The Iowa Gambling Task and the somatic marker hypothesis: Some questions and answers. Trends in Cognitive Sciences, 9(4), 159-162.

Benhsain, K., \& Ladouceur, R. (2004). Knowledge in statistics and erroneous perceptions in gambling. Gambling Research: Journal of the National Association for Gambling Studies, 16(1), 25-31.

Blaszczynski, A., \& McConaghy, N. (1989). Anxiety and/or depression in the pathogenesis of addictive gambling. Substance Use and Misuse, 24(4), 337-350.

Blaszczynski, A., \& Nower, L. (2002). A pathways model of problem and pathological gambling. Addiction, 97(5), 487-499.

Bottesi, G., Ghisi, M., Altoè, G., Conforti, E., Melli, G., \& Sica, C. (2015). The Italian version of the Depression Anxiety Stress Scales-21: Factor structure and psychometric properties on community and clinical samples. Comprehensive Psychiatry, 60, 170-181.

Brady, K. T., \& Lydiard, R. B. (1993). The association of alcoholism and anxiety. Psychiatric Quarterly, 64(2), 135149.

Brevers, D., Bechara, A., Cleeremans, A., \& Noël, X. (2013). Iowa Gambling Task (IGT): twenty years after-gambling disorder and IGT. Frontiers in Psychology, 4, 665. 
Brevers, D., Cleeremans, A., Goudriaan, A. E., Bechara, A., Kornreich, C., Verbanck, P., \& Noël, X. (2012). Decision making under ambiguity but not under risk is related to problem gambling severity. Psychiatry Research, 200, 568-574.

Ciccarelli, M., Griffiths, M. D., Nigro, G., \& Cosenza, M. (2016). Decision-making, cognitive distortions and alcohol use in adolescent problem and non-problem gamblers: An experimental study. Journal of Gambling Studies, 1-11.

Ciccarelli, M., Malinconico, R., Griffiths, M. D., Nigro, G., \& Cosenza, M. (2016). Reward preferences of pathological gamblers under conditions of uncertainty: An experimental study. Journal of Gambling Studies, 1-15.

Clark, L., Averbeck, B., Payer, D., Sescousse, G., Winstanley, C. A., \& Xue, G. (2013). Pathological choice: The neuroscience of gambling and gambling addiction. Journal of Neuroscience, 33(45), 17617-17623.

Coman, G. J., Burrows, G. D., \& Evans, B. J. (1997). Stress and anxiety as factors in the onset of problem gambling: Implications for treatment. Stress Medicine, 13(4), 235-244.

Cosenza, M., Baldassarre, I., Matarazzo, O., \& Nigro, G. (2014). Youth at stake: alexithymia, cognitive distortions, and problem gambling in late adolescents. Cognitive Computation, 6(4), 652-660.

Cosenza, M., Griffiths, M. D., Nigro, G., \& Ciccarelli, M. (2016). Risk-taking, delay discounting, and time perspective in adolescent gamblers: An experimental study. Journal of Gambling Studies, 1-13.

Cosenza, M., Matarazzo, O., Baldassarre, I., \& Nigro, G. (2014). Deciding with (or without) the future in mind: Individual differences in decision-making. In Recent Advances of Neural Network Models and Applications: Proceedings of the 23rd Workshop of the Italian Neural Networks Society (SIREN), May 23-25, Vietri sul Mare, Salerno, Italy (pp. 435-443). Cham, Switzerland: Springer International Publishing.

Cosenza, M., \& Nigro, G. (2015). Wagering the future: Cognitive distortions, impulsivity, delay discounting, and time perspective in adolescent gambling. Journal of Adolescence, 45, 56-66.

Damasio A. R. (1994). Descartes' error: Emotion, reason, and the human brain. Grosset/Putnam, New York.

Damasio, A. R., Tranel, D., \& Damasio, H. (1991). Somatic markers and the guidance of behavior: Theory and preliminary testing. In: Levin, H. S., Eisenberg, H. M., Benton, A. L. (eds.) Frontal Lobe Function and Dysfunction (pp. 217-229). New York: Oxford University Press.

Delfabbro, P., Lahn, J., \& Grabosky, P. (2006). It's not what you know, but how you use it: Statistical knowledge and adolescent problem gambling. Journal of Gambling Studies, 22(2), 179-193.

Dowling, N. A., Cowlishaw, S., Jackson, A. C., Merkouris, S. S., Francis, K. L., \& Christensen, D. R. (2015). Prevalence of psychiatric co-morbidity in treatment-seeking problem gamblers: A systematic review and metaanalysis. Australian and New Zealand Journal of Psychiatry, 49(6), 519-539. 
Dowling, N., Smith, D., \& Thomas, T. (2007). A comparison of individual and group cognitive-behavioural treatment for female pathological gambling. Behaviour Research and Therapy, 45(9), 2192-2202.

Dussault, F., Brendgen, M., Vitaro, F., Wanner, B., \& Tremblay, R. E. (2011). Longitudinal links between impulsivity, gambling problems and depressive symptoms: a transactional model from adolescence to early adulthood. Journal of Child Psychology and Psychiatry, 52(2), 130-138.

El-Guebaly, N., Patten, S. B., Currie, S., Williams, J. V., Beck, C. A., Maxwell, C. J., \& Wang, J. L. (2006). Epidemiological associations between gambling behavior, substance use \& mood and anxiety disorders. Journal of Gambling Studies, 22(3), 275-287.

Elman, I., Tschibelu, E., \& Borsook, D. (2010). Psychosocial stress and its relationship to gambling urges in individuals with pathological gambling. The American Journal on Addictions, 19(4), 332-339.

Fortune, E. E., \& Goodie, A. S. (2012). Cognitive distortions as a component and treatment focus of pathological gambling: A review. Psychology of Addictive Behaviors, 26(2), 298-310.

Friedland, N., Keinan, G., \& Regev, Y. (1992). Controlling the uncontrollable: effects of stress on illusory perceptions of controllability. Journal of Personality and Social Psychology, 63(6), 923-931.

Gaboury, A., \& Ladouceur, R. (1989). Erroneous perceptions and gambling. Journal of Social Behavior and Personality, 4(4), 411-420.

Gee, P., Coventry, K. R., \& Birkenhead, D. (2005). Mood state and gambling: Using mobile telephones to track emotions. British Journal of Psychology, 96(1), 53-66.

Goodie, A. S., \& Fortune, E. E. (2013). Measuring cognitive distortions in pathological gambling: Review and metaanalyses. Psychology of Addictive Behaviors, 27(3), 730-743.

Goudriaan, A. E., Oosterlaan, J., de Beurs, E., \& van den Brink, W. (2005). Decision making in pathological gambling: a comparison between pathological gamblers, alcohol dependents, persons with Tourette syndrome, and normal controls. Cognitive Brain Research, 23(1), 137-151.

Goudriaan, A. E., Oosterlaan, J., de Beurs, E., \& van den Brink, W. (2006). Psychophysiological determinants and concomitants of deficient decision making in pathological gamblers. Drug and Alcohol Dependence, 84(3), 231239.

Griffiths, M. D. (1994). The role of cognitive bias and skill in fruit machine gambling. British Journal of Psychology, 85(3), 351-369.

Griffiths, M. D. (1995). The role of subjective mood states in the maintenance of fruit machine gambling behaviour. Journal of Gambling Studies, 11(2), 123-135. 
Griffiths, M. D. (1999). The psychology of the near miss (revisited): A comment on Delfabbro and Winefield. British Journal of Psychology, 90, 441-445.

Griffiths, M. D. \& Bingham, C. (2005). A study of superstitious beliefs among bingo players. Journal of Gambling Issues, 13. Retrieved July 11, 2016, from: http://igi.camh.net/doi/full/10.4309/jgi.2005.13.7

Hills, A. M., Hill, S., Mamone, N., \& Dickerson, M. (2001). Induced mood and persistence at gaming. Addiction, 96(11), 1629-1638.

Hodgins, D. C., \& el-Guebaly, N. (2004). Retrospective and prospective reports of precipitants to relapse in pathological gambling. Journal of Consulting and Clinical Psychology, 72(1), 72-80.

Hodgins, D. C., Peden, N., \& Cassidy, E. (2005). The association between comorbidity and outcome in pathological gambling: A prospective follow-up of recent quitters. Journal of Gambling Studies, 21(3), 255-271.

Iliceto, P., Fino, E., Cammarota, C., Giovani, E., Petrucci, F., Desimoni, M., ... \& Oei, T. P. (2015). Factor structure and psychometric properties of the Italian version of the Gambling Related Cognitions Scale (GRCS-I). Journal of Gambling Studies, 31(1), 225-242.

Jacobsen, L. H., Knudsen, A. K., Krogh, E., Pallesen, S., \& Molde, H. (2007). An overview of cognitive mechanisms in pathological gambling. Nordic Psychology, 59(4), 347-361.

Joukhador, J., Blaszczynski, A., \& Maccallum, F. (2004). Superstitious beliefs in gambling among problem and nonproblem gamblers: Preliminary data. Journal of Gambling Studies, 20(2), 171-180.

Joukhador, J., Maccallum, F., \& Blaszczynski, A. (2003). Differences in cognitive distortions between problem and social gamblers. Psychological Reports, 92(3c), 1203-1214.

Källmén, H., Andersson, P., \& Andren, A. (2008). Are irrational beliefs and depressive mood more common among problem gamblers than non-gamblers? A survey study of Swedish problem gamblers and controls. Journal of Gambling Studies, 24(4), 441-450.

Kertzman, S., Lidogoster, H., Aizer, A., Kotler, M., \& Dannon, P. N. (2011). Risk-taking decisions in pathological gamblers is not a result of their impaired inhibition ability. Psychiatry Research, 188(1), 71-77.

Kessler, R. C., Hwang, I., LaBrie, R., Petukhova, M., Sampson, N. A., Winters, K. C., \& Shaffer, H. J. (2008). DSM-IV pathological gambling in the National Comorbidity Survey Replication. Psychological Medicine, 38(9), 13511360 .

Kim, S. W., Grant, J. E., Eckert, E. D., Faris, P. L., \& Hartman, B. K. (2006). Pathological gambling and mood disorders: Clinical associations and treatment implications. Journal of Affective Disorders, 92(1), 109-116.

Ladouceur, R. (2004). Perceptions among pathological and nonpathological gamblers. Addictive Behaviors, 29(3), 555565. 
Ladouceur, R., Sylvain, C., Boutin, C., Lachance, S., Doucet, C., \& Leblond, J. (2003). Group therapy for pathological gamblers: A cognitive approach. Behaviour Research and Therapy, 41(5), 587-596.

Ladouceur, R., Sylvain, C., Boutin, C., Lachance, S., Doucet, C., Leblond, J., \& Jacques, C. (2001). Cognitive treatment of pathological gambling. Journal of Nervous and Mental Disease, 189(11), 774-780.

Ladouceur, R., Sylvain, C., Sévigny, S., Poirier, L., Brisson, L., Dias, C., ... \& Pilote, P. (2006). Pathological gamblers: Inpatients' versus outpatients' characteristics. Journal of Gambling Studies, 22(4), 443-450.

Lakey, C. E., Goodie, A. S., \& Campbell, W. K. (2007). Frequent card playing and pathological gambling: The utility of the Georgia Gambling Task and Iowa Gambling Task for predicting pathology. Journal of Gambling Studies, 23(3), 285-297.

Lesieur, H. R. (1979). The compulsive gambler's spiral of options and involvement. Psychiatry, 42(1), 79-87.

Lesieur, H. R., \& Blume, S. B. (1987). The South Oaks Gambling Screen (SOGS): A new instrument for the identification of pathological gamblers. American Journal of Psychiatry, 144, 1184-1188.

Linnet, J., Røjskjær, S., Nygaard, J., \& Maher, B. A. (2006). Episodic chasing in pathological gamblers using the Iowa gambling task. Scandinavian Journal of Psychology, 47(1), 43-49.

Lorains, F. K., Cowlishaw, S., \& Thomas, S. A. (2011). Prevalence of comorbid disorders in problem and pathological gambling: systematic review and meta-analysis of population surveys. Addiction, 106(3), 490-498.

Lorains, F. K., Dowling, N. A., Enticott, P. G., Bradshaw, J. L., Trueblood, J. S., \& Stout, J. C. (2014). Strategic and non-strategic problem gamblers differ on decision-making under risk and ambiguity. Addiction, 109(7), 11281137.

Lovibond, P. F., \& Lovibond, S. H. (1995). The structure of negative emotional states: Comparison of the Depression Anxiety Stress Scales (DASS) with the Beck Depression and Anxiety Inventories. Behaviour Research and Therapy, 33(3), 335-343.

Matthews, N., Farnsworth, B., \& Griffiths, M. D. (2009). A pilot study of problem gambling among student online gamblers: mood states as predictors of problematic behavior. CyberPsychology and Behavior, 12(6), 741-745.

McCartney, J. (1995). Addictive behaviors: Relationship factors and their perceived influence on change. Genetic, Social, and General Psychology Monographs, 121(1), 39-64.

Miller, N. V., \& Currie, S. R. (2008). A Canadian population level analysis of the roles of irrational gambling cognitions and risky gambling practices as correlates of gambling intensity and pathological gambling. Journal of Gambling Studies, 24(3), 257-274.

Mishra, S., Morgan, M., Lalumiere, M. L., \& Williams, R. J. (2010). Mood and audience effects on video lottery terminal gambling. Journal of Gambling Studies, 26(3), 373-386. 
Myrseth, H., Brunborg, G. S., \& Eidem, M. (2010). Differences in cognitive distortions between pathological and nonpathological gamblers with preferences for chance or skill games. Journal of Gambling Studies, 26(4), 561-569.

Nigro, G., Cosenza, M., Ciccarelli, M., \& Joireman, J. (2016). An Italian translation and validation of the Consideration of Future Consequences-14 Scale. Personality and Individual Differences, 101, 333-340.

Nower, L., \& Blaszczynski, A. (2010). Gambling motivations, money-limiting strategies, and precommitment preferences of problem versus non-problem gamblers. Journal of Gambling Studies, 26(3), 361-372.

Oei, T. P., Lin, J., \& Raylu, N. (2008). The relationship between gambling cognitions, psychological states, and gambling a cross-cultural study of Chinese and Caucasians in Australia. Journal of Cross-Cultural Psychology, $39(2), 147-161$.

Petry, N. M. (2001). Substance abuse, pathological gambling, and impulsiveness. Drug and Alcohol Dependence, 63(1), 29-38.

Petry, N. M., Stinson, F. S., \& Grant, B. F. (2005). Comorbidity of DSM-IV pathological gambling and other psychiatric disorders: results from the National Epidemiologic Survey on Alcohol and Related Conditions. Journal of Clinical Psychiatry, 66(5), 564-574.

Quigley, L., Yakovenko, I., Hodgins, D. C., Dobson, K. S., el-Guebaly, N., Casey, D. M., ... \& Schopflocher, D. P. (2015). Comorbid problem gambling and major depression in a community sample. Journal of Gambling Studies, 31(4), 1135-1152.

Raylu N. and Oei T. P., The Gambling Related Cognitions Scale (GRCS): Development, confirmatory factor validation and psychometric properties, Addiction, 99 (6), 2004, 757-769.

Raylu, N., \& Oei, T. P. (2002). Pathological gambling: A comprehensive review. Clinical Psychology Review, 22(7), 1009-1061.

Reith, G. (2002). The age of chance: Gambling in western culture. London: Routledge.

Sévigny, S., \& Ladouceur, R. (2003). Gamblers' irrational thinking about chance events: The 'double switching' concept. International Gambling Studies, 3(2), 149-161.

Ste-Marie, C., Gupta, R., \& Derevensky, J. L. (2006). Anxiety and social stress related to adolescent gambling behavior and substance use. Journal of Child and Adolescent Substance Abuse, 15(4), 55-74.

Stewart, S. H., Zack, M., Collins, P., Klein, R. M., \& Fragopoulos, F. (2008). Subtyping pathological gamblers on the basis of affective motivations for gambling: relations to gambling problems, drinking problems, and affective motivations for drinking. Psychology of Addictive Behaviors, 22(2), 257-268. 
Taylor, R. N., Parker, J. D., Keefer, K. V., Kloosterman, P. H., \& Summerfeldt, L. J. (2014). Are gambling related cognitions in adolescence multidimensional?: Factor structure of the gambling related cognitions scale. Journal of Gambling Studies, 30(2), 453-465.

Taylor, R. N., Parker, J. D., Keefer, K. V., Kloosterman, P. H., \& Summerfeldt, L. J. (2015). Gambling related cognitive distortions in adolescence: Relationships with gambling problems in typically developing and special needs students. Journal of Gambling Studies, 31(4), 1417-1429.

Thomsen, K. R., Callesen, M. B., Linnet, J., Kringelbach, M. L., \& Møller, A. (2009). Severity of gambling is associated with severity of depressive symptoms in pathological gamblers. Behavioural Pharmacology, 20(5-6), $527-536$.

Toneatto, T. (1999). Cognitive psychopathology of problem gambling. Substance Use \& Misuse, 34(11), $1593-1604$.

Toneatto, T., \& Pillai, S. (2016). Mood and anxiety disorders are the most prevalent psychiatric disorders among pathological and recovered gamblers. International Journal of Mental Health and Addiction, 14(3), 217-227..

Wiehler, A., \& Peters, J. (2015). Reward-based decision making in pathological gambling: The roles of risk and delay. Neuroscience Research, 90, 3-14.

Wood, R. T., \& Griffiths, M. D. (2007). A qualitative investigation of problem gambling as an escape-based coping strategy. Psychology and Psychotherapy: Theory, Research and Practice, 80(1), 107-125.

Wulfert, E., Roland, B. D., Hartley, J., Wang, N., \& Franco, C. (2005). Heart rate arousal and excitement in gambling: winners versus losers. Psychology of Addictive Behaviors, 19(3), 311-316. 
Table 1. Pearson correlation coefficients among all variables

\begin{tabular}{|c|c|c|c|c|c|c|c|c|c|c|c|}
\hline & 1 & 2 & 3 & 4 & 5 & 6 & 7 & 8 & 9 & 10 & 11 \\
\hline 1. SOGS & - & & & & & & & & & & \\
\hline 2. GRCS-GE & $.48 * *$ & - & & & & & & & & & \\
\hline 3. GRCS-IC & $.48 * *$ & $.69 * *$ & - & & & & & & & & \\
\hline 4. GRCS-PC & $.48 * *$ & $.77^{* * *}$ & $.67 * *$ & - & & & & & & & \\
\hline 5. GRCS-IS & $.55 \% *$ & $.82 * *$ & $.71^{* * *}$ & $.82 * *$ & - & & & & & & \\
\hline 6. GRCS-IB & $.52 * *$ & $.80^{* * *}$ & $.72 * *$ & $.89 * *$ & $.93 * *$ & - & & & & & \\
\hline 7. GRCS & $.55 * *$ & .89 *** & $.80^{* * *}$ & $.92 * *$ & $.95 * *$ & $.97 * *$ & - & & & & \\
\hline 8. DASS-D & $.39 * *$ & .12 & .16 & .13 & .14 & .10 & .14 & - & & & \\
\hline 9. DASS-A & $.22 *$ & .02 & .12 & .13 & .10 & .05 & .09 & $.76 * *$ & - & & \\
\hline 10. DASS-S & .16 & .00 & .05 & .05 & .02 & -.01 & .02 & $.66^{* * *}$ & $.73 * *$ & - & \\
\hline 11. DASS-21 & $.28 * *$ & .05 & .12 & .12 & .10 & .05 & .09 & .90 ** & $.92 * *$ & $.89 * *$ & - \\
\hline 12. IGT & $-.36^{* * *}$ & $-.22 *$ & $\begin{array}{l}.09 \\
\end{array}$ & $-.27 * *$ & $-.21 *$ & $-.21 *$ & $-.23 *$ & -.09 & $\begin{array}{l}.09 \\
\end{array}$ & -.08 & -.09 \\
\hline
\end{tabular}

Note. Bold values represent significant correlation coefficients.

SOGS= South Oaks Gambling Screen; GRCS-GE= Gambling Expectances scale of GRCS; GRCS-IC= Illusion of Control scale of GRCS; GRCS$\mathrm{PC}=$ Predictive Control scale of GRCS; GRCS-IS= Inability to Stop scale of GRCS; GRCS-IB= Interpretative Bias scale of GRCS; GRCS= Gambling Related Cognition Scale Total Score; DASS-D= Depression scale of DASS-21; DASS-A= Anxiety scale of DASS-21; DASS-S= Stress scale of DASS-21; DASS-21 = Depression Anxiety Stress Scale Total Score; IGT= Iowa Gambling Task. 
Table 2. Means and standard deviations on the self-report measures for healthy control (HCs), and pathological gambler (PGs) groups.

\begin{tabular}{|c|c|c|c|c|c|c|c|}
\hline & \multicolumn{2}{|c|}{ HCs $(N=54)$} & \multicolumn{2}{|c|}{ PGs $(N=54)$} & \multirow[b]{2}{*}{$F_{1,106}$} & \multirow[b]{2}{*}{$p<$} & \multirow[b]{2}{*}{$\eta^{2} p$} \\
\hline & $M$ & $S D$ & $M$ & $S D$ & & & \\
\hline GRCS-GE & 2.08 & 1.13 & 6.39 & 6.19 & 25.33 & .001 & .19 \\
\hline GRCS-IC & 1.57 & 0.88 & 4.46 & 4.63 & 20.23 & .001 & .16 \\
\hline GRCS-PC & 1.99 & 1.15 & 7.78 & 7.82 & 28.96 & .001 & .21 \\
\hline GRCS-IS & 1.77 & 1.06 & 10.03 & 9.46 & .40 .66 & .001 & .28 \\
\hline GRCS-IB & 2.31 & 1.38 & 9.39 & 8.41 & 37.18 & .001 & .26 \\
\hline GRCS & 9.74 & 4.83 & 38.06 & 32.78 & 39.44 & .001 & .27 \\
\hline DASS-D & 6.26 & 8.15 & 13.57 & 9.72 & 17.96 & .001 & .14 \\
\hline DASS-A & 5.81 & 8.19 & 10.41 & 9.01 & 7.69 & .01 & .07 \\
\hline DASS-S & 10.04 & 8.79 & 13.41 & 10.24 & 3.36 & $\mathrm{~ns}$ & \\
\hline DASS-21 & 22.11 & 22.18 & 37.39 & 26.23 & 10.68 & .01 & .09 \\
\hline
\end{tabular}

Note. GRCS-GE = Gambling Expectances scale of GRCS; GRCS-IC = Illusion of Control scale of GRCS; GRCS-PC = Predictive Control scale of GRCS; GRCS-IS = Inability to Stop scale of GRCS; GRCS-IB = Interpretative Bias scale of GRCS; GRCS = Gambling Related Cognition Scale Total Score; DASS-D = Depression scale of DASS-21; DASS-A = Anxiety scale of DASS-21; DASS-S = Stress scale of DASS-21; DASS-21 = Depression Anxiety Stress Scale Total Score. 
Table 3. Multivariate prediction of severity of gambling problems with a logistic regression model

\begin{tabular}{|l|c|c|c|c|}
\hline Predictors & Beta & S.E. & $\begin{array}{c}\text { Wald } \\
\text { statistic }\end{array}$ & $\begin{array}{c}p \\
\text { value }\end{array}$ \\
\hline Step 1 & & & & 0.001 \\
\hline GRCS & 0.084 & 0.026 & 10.35 & \\
\hline Step 2 & & & & 0.001 \\
\hline GRCS & 0.077 & 0.023 & 11.62 & 0.009 \\
\hline DASS-21 & 0.024 & 0.009 & 6.91 & 0.001 \\
\hline Step 3 & & & & 0.009 \\
\hline GRCS & 0.072 & 0.022 & 11.23 & 0.022 \\
\hline DASS-21 & 0.025 & 0.010 & 6.74 & 5.26 \\
\hline IGT & -0.019 & 0.008 & & \\
\hline
\end{tabular}

Note. GRCS = Gambling Related Cognition Scale; DASS-21 = Depression Anxiety Stress Scale; IGT = Iowa Gambling Task 


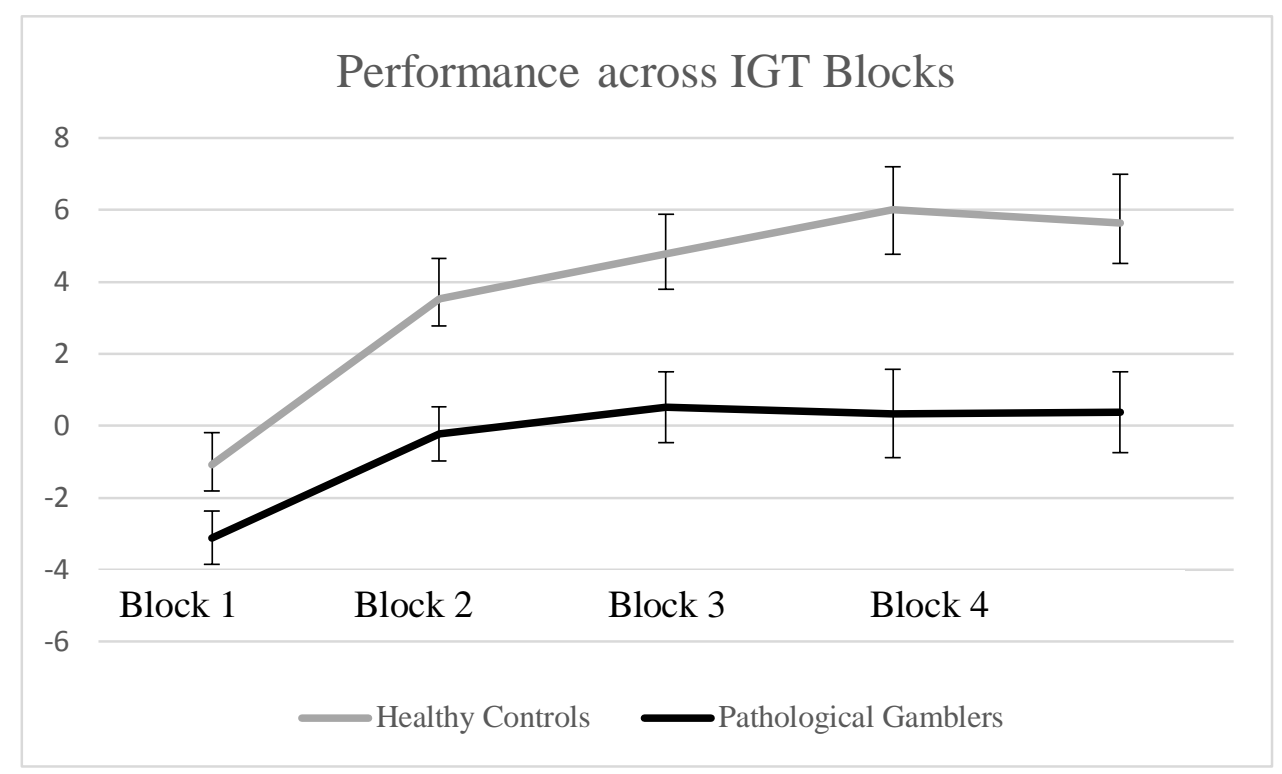

Figure 1. Profiles for the mean number (and standard errors) of cards chosen from advantageous minus disadvantageous decks over the five IGT blocks as function of Group. 